\title{
Multiple Endocrine Neoplasia Type 2B Due to the M918T Mutation de Novo at Algiers
}

\author{
Ammar Chikouche ${ }^{1 *}$, Nadia Ould Bessi ${ }^{1}$, Nawel Habak ${ }^{1}$ and Mebarek Boudissa ${ }^{2}$ \\ ${ }^{1}$ Laboratory of Biochemistry, Pierre and Marie Curie Center, Algeria \\ ${ }^{2}$ Endocrinology Department, Pierre and Marie Curie Center, Algeria \\ *Corresponding author: Ammar Chikouche, Laboratory of Biochemistry, Pierre and Marie Curie Center, Algiers, Algeria. \\ To Cite This Article: Ammar C, Nadia Ould B, Nawel H, Mebarek B. Multiple Endocrine Neoplasia Type 2B Due to the M918T Mutation de Novo \\ at Algiers. Am J Biomed Sci \& Res. 2020 - 11(3). AJBSR.MS.ID.001627. DOI: 10.34297/AJBSR.2020.11.001627.
}

Received: 眥 November 25, 2020; Published: 眥 December 17, 2020

\begin{abstract}
Summary
Multiple Endocrine Neoplasia type2B (MEN2B) associates Medullar Thyroid Cancer (MTC), pheochromocytoma, gastrointestinal disorders, marphanoid face, and mucosal multiple ganglioneuroma.

The MEN2B belongs MEN2 which are hereditary diseases related to mutations of RET proto-oncogene. Genotypic analysis is indicated in any case MEN2B and involved the detection of mutations in the RET gene. Samples of two patients aged 23, 22 and 20 years of 03 different families diagnosed MEN2B were analyzed. The genetics analysis also covers 10 members of the 03 families. It was realized, after DNA extraction from whole blood by the method to salts, by amplification of exons by PCR followed by sequencing on Applied Biosystems ABI 3130 and concerned the exons 15 and 16. Germline mutation M918T, located at exon 16 in heterozygous form, was found in the 03 index cases MEN2B.
\end{abstract}

The discovery of this mutation, highly specific (95\%) of the MEN2B confirms the family form. Genetic screening related that has not found the mutation in other family members, can be concluded that this mutation is de Novo, as found in the literature.

Keywords: Multiple endocrine neoplasia type 2B; Medullary thyroid carcinoma; Protooncogene RET; Mutation; Genetic screening

\section{Introduction}

Multiple Endocrine Neoplasia type 2B (MEN2B), or Gorlin syndrome [1], is a very rare condition. It corresponds to the association of a MTC (100\% of cases), a pheochromocytoma (50\% of cases), musculoskeletal abnormalities (15 to $20 \%$ of cases), developmental abnormalities and mucosal neurons, without hyperparathyroidism.

It is the most aggressive and rare form (5\%) of MEN2. MEN2 are rare hereditary diseases, transmitted according to the autosomal dominant mode [2], related to mutations of the proto-oncogene RET (rearranged during transfection) [3].

The RET gene identified by Takahashi in 1985 [4] and located on chromosome 10 (10q11.2) by Ishizaka in 1989 [5]. It consists of 21 exons [6,7] codes for a protein (transmembrane receptor with tyrosine kinase activity) [4]. The RET receptor consists of an extracellular part rich in cysteines, a transmembrane domain and an intracellular region with tyrosine kinase activity [8].
The activation of the RET receptor proceeds in the following manner: a homodimeric ligand of the GFL family (GDNF Family Ligand) whether it be GDNF (Glial cell line-Derived Neurotrophic Factor), Neurturin, Artemin or Persephin linked to a specific GFR $\alpha$ receptor (GDNF family receptors- $\alpha 1$ to 4 ). The ligand-coreceptor binding in dimeric form causes the dimerization of the RET receptor and its activation [9].

During MEN2B, mutations occur at the intracytoplasmic region with tyrosine kinase activity (essentially Met 918) and in this case the RET receptor is constitutively active as a monomer, which in turn leads to abnormal phosphorylation. of its intracellular substrate proteins [10].

Before a case of MEN2B whose diagnosis is clinical and biological, the genotypic analysis is necessary and is based on the demonstration of mutations of the RET gene, in exons 16 and 15. The identification of these mutations by molecular biology techniques 
confirms the diagnosis of MEN2. Therefore, it recommends to look for, in all index cases, a mutation in the coding regions of the protooncogene RET likely to be mutated during the MEN2B to search for the family mutation found in relatives. Molecular screening has taken an important place in family forms in search of relatives carrying the family mutation.

This will make it possible to discern the carriers and noncarriers of the mutation.

\section{Materials and Methods}

We received blood samples from 03 patients belonging to 03 different families diagnosed as MEN2B. A 23-year-old patient from a sibling of 03 , a 22-year-old patient from a sibling of 03 and a 20-year-old patient from a sibling of 06 children.

The whole blood samples were taken on tube with EDTA. A request for a genotypic analysis was sent to us accompanied by a letter of consent and a sheet where the diagnosis is given, a clinical summary and a report of the biological exploration and imaging with each sample.

Subsequently samples of the relatives of the 03 index cases were sent to us. The genetic study was conducted in patient $\mathrm{N}^{\circ} 1$, her sister and mother, patient $\mathrm{N}^{\circ} 2$, her brother and patient $\mathrm{N}^{\circ} 3$, her father, mother, and siblings (Table 1 ) as shown on family trees (Figure 1)

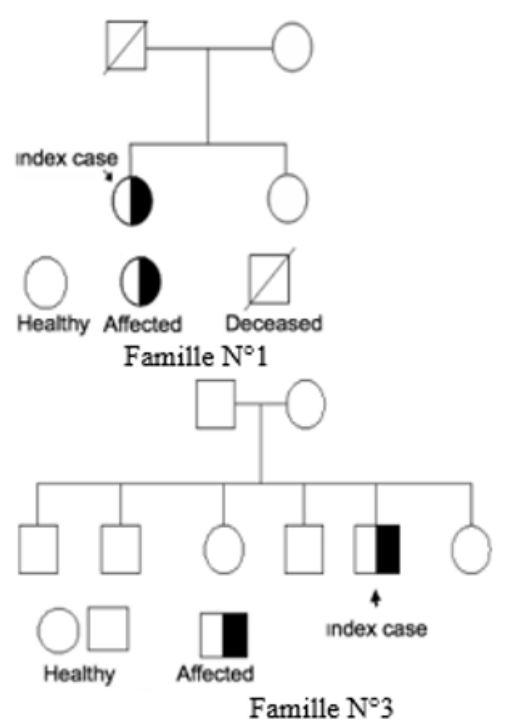

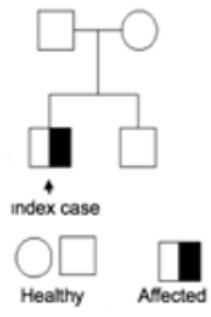

Famille $\mathrm{N}^{\circ} 2$

Figure 1: Family pedigree of the 03 families.

Table 1: Results of genotypic study in index cases and relatives.

\begin{tabular}{|c|c|c|c|c|c|}
\hline \multicolumn{2}{|c|}{ Family 1 } & \multicolumn{2}{c|}{ Family 2 } & \multicolumn{2}{c|}{ Family 3 } \\
\hline Subject studied & Mutation & Subject studied & Mutation & Subject studied & Mutation \\
\hline Case index & Positive & Case index & Positive & Case index & Positive \\
\hline Mother & Negative & Brother & Négative & Father & Negative \\
\hline Sister & Negative & & & Mother & Negative \\
\hline
\end{tabular}

It was mentioned that the father of patient $\mathrm{N}^{\circ} 1$ died of a cause unrelated to the MEN2. The parents of Patient $\mathrm{N}^{\circ} 2$ are completely free of MEN2. Genomic DNA was extracted from peripheral blood leukocytes by the salt technique. A decision algorithm was decided according to the order of the most frequently mutated exon.

The genetic study concerned exons 15 and 16. It was carried out by exon amplification by PCR followed by sequencing on ABI 3130 Applied Biosystems.
The amplification of exon 16 of the RET proto-oncogene was performed using the following primers provided by Applied Bio Systems.

\section{RET 16F: 5’ CAT CTC AGC AAT CCA CAG GA 3'}

\section{RET 16R: 5’ TTG CCT CAC GAA CAC ATC AT 3'}

The PCR conditions used are $4 \mu \mathrm{l}$ of DNA (25 ng / $\mu \mathrm{l}$ ), $2.5 \mu \mathrm{l} \mu \mathrm{l}$ of 10X PCR buffer; $1.25 \mu \mathrm{l}$ of dNTPs ( $2 \mathrm{mM}, 1.5 \mu \mathrm{l} 25 \mathrm{mM} \mathrm{MgCl} 2$, 
$1.25 \mu \mathrm{l}$ of $2 \mathrm{mM}$ dNTPs, $1.25 \mu \mathrm{l}$ of $5 \mathrm{pmol} / \mu \mathrm{l}$ sense and antisense primers), $0.1 \mu \mathrm{l}$ Taq polymerase Roche $(5 \mathrm{U} / \mu \mathrm{I})$ and $13.15 \mu \mathrm{I}$ of $\mathrm{H}_{2} \mathrm{O}$.

The amplification is programmed as follows; an initial denaturation step of 5 minutes at $94^{\circ} \mathrm{C}$., then 35 amplification cycles (comprising denaturation of one minute at $94^{\circ} \mathrm{C}$., hybridization of one minute at $60^{\circ} \mathrm{C}$. and elongation of one minute at $72^{\circ} \mathrm{C}$.) followed by a final elongation step of 10 minutes at $72^{\circ} \mathrm{C}$.

The amplicons are tested by electrophoresis in $2 \%$ agarose gel with Roche Size VII marker. The size of the amplicon 13 is $250 \mathrm{bp}$.

\section{Sequence PCR}

The PCR products are purified on Millipore (Manu 30) plates and the sequence PCR reaction is carried out with $1.5 \mu \mathrm{l}$ of purified PCR product; $0.8 \mu \mathrm{l}$ of Big Dye terminator V1.1 (Applied Biosystem); $3.6 \mu \mathrm{l}$ of $5 \mathrm{X}$ buffer (V1.1) and $2 \mu \mathrm{l}$ of sense or antisense primer ( 5 $\mathrm{pmol} / \mu \mathrm{l})$.

The amplification is programmed with 25 cycles comprising a step of 30 seconds at $95^{\circ} \mathrm{C}$ followed by a step of 4 minutes at $60^{\circ} \mathrm{C}$.

The sequence PCR products are purified to remove dNTPs, unincorporated free dideoxynucleotides and excess primers by a method based on the use of Sephadex G 50 gel on MultiScreen MAHV N45 plates (Millipore).

The purified sequence PCR products are passed to the Applied Bio System 3130 Sequencer which performs capillary electrophoresis using POP 7 gel (Applied Biosystems).

\section{Results and Discussion}

We found in the 03 patients (index case) the same mutation which is the M918T localized in exon 16 in heterozygous form. This mutation is due to a base substitution, a $\mathrm{T}>\mathrm{C}$ transition at nucleotide c. 2753 , in the heterozygous form, the ATG codon will give the ACG codon. This will change the methionine at position 918 to threonine.

After the mutation in the index cases was detected, a study of 03 families (Table 1 \& Figure 1) was performed. Apparently healthy relatives have benefited from genotypic analysis.

The No.1 family consists of the female index case, her mother and her sister.

The No.2 family consists of the male index case and his brother.

The family No. 3 composed of male index case, his father, his mother, 03 brothers and 02 sisters.

This mutation was not found in the other members of the families studied.
The M918T mutation, which we identified in our 03 cases of MEN2B (Figure 2), is very commonly found in the case of MEN2B in the literature [11,12].

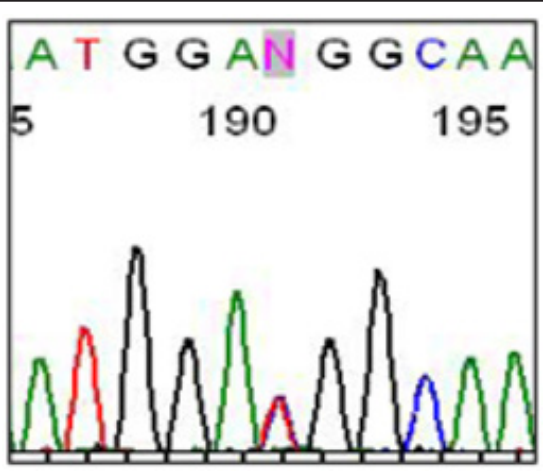

Figure 2: Profile of the M918T mutation in sense.

It is part of the specific mutations of MEN2B. These mutations are essentially represented by the codon 918 (M918T; exon 16) mutation, which is highly specific (95\%) [11,12]; codon 883 mutation (A883F, exon 15) is less common (5\%) [13,14].

The M918T substitution is frequently a de novo mutation located on the allele inherited from the patient's father $[8,15]$. This substitution of M918T is also found somatically in sporadic thyroid carcinoma (MTC). Tumors with this M918T mutation often exhibit an aggressive phenotype. Parents who are not carriers of the mutation should not benefit from medical care and are therefore reassured. It is not necessary to perform genotypic studies of other relatives except for the children of the 03 patients.

\section{Conclusion}

The discovery of the M918T germline mutation in the 03 MEN2B index cases confirms the clinico-biological diagnosis of familial form. This codon 918 mutation, the M918T at exon 16 is highly specific (95\%) of the MEN2B. Genetic screening of relatives who have not found the mutation in other members of the family, allows us to conclude that this mutation is de novo (neomutation) as it has been described in the literature.

Relatives who do not carry the mutation are considered free and thus do not benefit from any medical supervision.

\section{Acknowledgement}

We thank Dr. Daoud Chafia for assisting in the development of this article and we express our gratitude.

No conflict of interest related to the article exists.

\section{References}

1. Gorlin RJ, Sedano HO, Vickers RA, Cervenja J (1968) Multiple mucosal neuromas, pheochromocytoma and medullary carcinoma of the thyroid: a syndrome. Cancer 22(2): 293-296. 
2. Santoro M, Carlomagno F, Romano A, Bottaro DP, Dathan NA, et al (1995) Activation of RET as a dominant transforming gene by germline mutations of MEN2A and MEN2B. Science 267(5196): 381-383.

3. Hofstra RMW, Landsvater RM, Ceccherini I, Stulp RP, Stelwagen T, et al. (1994) A mutation in the RET protooncogene associated with multiple endocrine neoplasia type $2 \mathrm{~B}$ and sporadic medullary thyroid carcinoma. Nature 367(6461): 375-376.

4. Takahashi M, Ritz J, Cooper GM (1985) Activation of a novel human transforming gene, RET, by DNA rearrangement. Cell 42(2): 581-588.

5. Ishizaka Y, Itoh F, Tahira T, Ikeda I, Sugimura T, et al. (1989) Human ret proto-oncogene mapped to chromosome 10q11.2. Oncogene $4(12)$ 1519-1521.

6. Kwok JB, Gardner E, Warner JP, Ponder BA, Mulligan LM (1993) Structural analysis of the human RET proto-oncogene using exon trapping. Oncogene 8(9): 2575-2582.

7. Myers SM, Eng C, Ponder BA, Mulligan LM (1995) Characterization of RET proto-oncogene 3_ splicing variants and polyadenylation sites: a novel C-terminus for RET. Oncogene 11: 2039-2045.

8. Arighi E, Borrello MG, Sariola H (2005) RET tyrosine kinase signaling in development and cancer. Cytokine Growth Factor Rev 16(4-5): 441-467.
9. Airaksinen MS. Saarma M (200) The GDNF Family: Signaling, biological, functions and thérapeutic value (Review). Nature Reviews | Neuroscience 3(5): 383-394.

10. Plaza-Menacho I. Functional analysis of RET in MEN2; University Groningen, Hollande, these; 2006.

11. Carlson KM, Dou S, Chi D, Scavarda N, Toshima K, et al. (1994) Single missense mutation in the tyrosine kinase catalytic domain of the RET protooncogene is associated with multiple endocrine neoplasia type 2B. Proc Natl Acad Sci 91: 1579-1583.

12. Hansford JR, Mulligan LM (2000) Multiple endocrine neoplasia type 2 and RET: from neoplasia to neurogenesis. J Med Genet 37(11): 817-827.

13. Gimm O, Marsh DJ, Andrew SD, Frilling A, Dahia PL, et al. (1997) Germline dinucleotide mutation in codon 883 of the RET proto-oncogene in multiple endocrine neoplasia type 2B without codon 918 mutation. J Clin Endocrinol Metab 82(11): 3902-3904.

14. Smith DP, Houghton C, Ponder BA (1997) Germline mutation of RET codon 883 in two cases of de novo MEN 2B. Oncogene 15(10): 12131217.

15. Carlson KM, Bracamontes J, Jackson CE, Clark R, Lacroix A, et al. (1994) Parent-of-origin effects in multiple endocrine neoplasia type $2 \mathrm{~B}$. Am J Hum Genet 55(6): 1076-1082. 